\title{
The development of cognitive independence of students of the University through networking cooperation
}

\author{
Vladimir N. Eliseev ${ }^{1, *}$ \\ ${ }^{1}$ Moscow Technological Institute, 199334, Moscow, Russia
}

\begin{abstract}
The paper describes the aspects of the augmented reality application development on the base of ARToolkit for Android. The steps consistently used for the augmented reality application development have been considered. The simplest Java-based examples of augmented reality have been discussed.
\end{abstract}

\section{Introduction}

The world is embracing the age of electronic activity, network communities and organizations without boundaries. The new age is radically changing the economic and social aspects of life of the society. The problem of a man is an axial principle of understanding and cognition of a modern world, which are based on two interrelated processes: the growth of information and information technologies and the change of earlier schemes of interaction of the man with the surrounding reality. The growth of information itself does not create an information society. The information should be socialized, i. e. to be discovered, in demand and used by the man. Thus, the avalanche-like development of information and technologies makes the world dependent on human factor and human resource.

Informatization of education is a process of training the man for a proper life in the condition of information society, where there is a need of abilities and skills to plan their activity, search for required information to solve the arising tasks as well as use modern technical means of different activity types.

Informatization of university education is defined as a process of intellectualization of a student and teacher's activity, which develops on the basis of realization of resources of information technologies, supports the integration tendencies of the process of cognition of regularities of subject fields and environment (social, ecological, information etc.), combining them with the advantages individualization and differentiation of learning [1].

The current objective of modern education is the development of cognitive independence as globalization of university education, modern tendencies of university education create the demand for information technologies in university education (both objectively and subjectively); moreover, the main aspect is the ability to promptly deal with the information.
Cognitive independence is seen as integrative personal quality that is characterized by sufficient level of knowledge, value attitude to cognition and combination of information abilities that ensure student's successful personal solution of educational and professionally-oriented tasks with implementation of information technologies [2].

Mastering of information technology contributes to both intellectual development and formation of a student's notion about the global picture of the world. It should be noted that a computer is a means of education and professional development, expansion of professional competence level. Thus the most important function of modern education is to provide students with not so much volume or content of knowledge as ways to obtain it.

\section{Analysis and discussion}

One of the main conditions for the development of information-informative independence of students of the University is a network of educational interaction.

Let's determine the definitions that are important for this work: «network», «educational network», «network cooperation», «network pedagogical impact», «network sectorial educational program».

Network is a base structure of social system of information interaction built on the principles of distributed processing of data. Its main peculiarity is almost immediate transfer of different structural object descriptions to any place in the world provided there are modern means of communication and connection there. Electronic network is based on special space and time configuration of communication traffic and relations, which ensures simultaneousness of practical actions of people who are at a gigantic distance away from each other. The topography of geographical orienting points does not disappear, but their logic and meaning as the system of coordinates gain space and time independence.

Corresponding author: evsei86@mail.ru 
Educational network is the combination of subjects of educational activity, who provide personal educational resources to each other in order to improve the performance and quality of each other's education (A. I. Adamsky).

Network cooperation is a modern highly efficient innovation technology that allows educational institutions to develop dynamically. At the same time, there is not only spread of innovation developments during the network cooperation, but also the process of a dialogue between an educational institution and the process of reflection in them the experience of one another, reflection of those processes, which tale place in the system of education as a whole.

Network pedagogical impact is a system of relations that allow developing, testing and presenting innovation models of education content and educational system management to pedagogical community; it is a way of activity on joint use of educational resources.

Network sectorial educational program is a document designed by several organizations performing educational activity. It determines: a) content and volume of educational material, modules (hours and examination units); b) order of program learning (coherent theoretical and practical learning); c) conditions of learning (form, terms and cost of education, evaluation of quality, final document); d) requirements to performers (level of qualification and responsibility).

The theory of systems serves as a methodological base of network educational cooperation (A. Bogdanov, L. von Bertalanffy, W. Ashby, M. Mesarovich, A. I. Uyomov, M. Weber, T. Parsons, R. Ackoff, B. Milner, S. Robbins etc.).

The theory of social networks analyzes different forms of cooperation between subjects (individuals and organizations) from the point of topological relation, their stability and impact on behavior of these subjects. This theory started forming 50 years ago. The pioneers were the representatives of sociology and social psychology, who were oriented to studying the role of human interactions in the development of any structure from the very beginning. A. Bavelas and H. Levitt proposed to define network as the combination of positions, not individuals. Final model of relations between positions, obtained by them in the course of experiments, looked as a base or a type of structure. The first mentioning of a central is found in the works of A. Bavelas (when communication was carried out through a central position, certain tasks were performed quicker and in a more qualitative manner).

M. Granovetter defines the social network as a combination of three components: combination of positions, networks (relations); flows of resources. He also talks about social capital, the combination of relations and assets place in the given network. It is close to the definition of P. Bourdieu, who was the first to undertake the systematic analysis of social capital and defined it as « the aggregate of the actual or potential resources which are linked to possession of a durable network of more or less institutionalized relationships of mutual acquaintance or recognition»».
Today, the basic accent in the research of network structures falls on the studying of changes of communicative experience of a modern man taking place due to the implementation of modern technologies of information exchange.

M. Castells considers the network space as global architectural structure of a new form, where the space of places displaces the space of flows. The flows of information running in the network avoid experience personified in everything that is local. Network virtuality acts as a field of out-of-time, deprived of place symbolic systems on the basis of which a new information and technology paradigm is formed. Its distinctive feature is flexibility as new configuration is noted for the ability of constant reconfiguration. This factor should be taken as competitive advantage of modern conditions as constant change and organizational fluctuation is typical of the modern society. On this base of the experiment the man forms images, personal behavior and style of thinking. M. Castells emphasizes that information and technology paradigm evolves not towards its closing as a system, but its opening as multi-sided network [3].

K. Kelly distinguishes certain properties of network logic. He claims that a dynamic network with terribly difficult complexity will be the symbol of science of XXI century. Network organization has features of selforganizing fields. It is capable of «growth or independent learning free from prejudices» [4].

R. Stichweh believes that the theory of non-local activity has certain explanatory potential and focuses the fact that the relations of observation and comparison take place between the units separated from one another by long distances [5]. Direct contact between them is not necessary. Effects of local action prevail in the traditional experience of culture, which postulate local spread of actions having global impact. Referring to the examination of nature of structural innovations ensuring the formation of world society, R. Stichweh comes to conclusion about the principle of network exchange. This principle is based on the functioning of the forms of symmetrical and asymmetrical exchange. Under this understanding, the notion of network serves as indication of universal method and theory related to the study of nature of structural changes.

In the context of study of issues of network cooperation, there is an interesting strategy of development and management «Theory of mutual motivation of six networks» (Li Jin Yuan). «Six networks» presuppose human resources, education, logistics, tourism, international capital turnover and Internet. «Theory of mutual motivation of six networks» is simultaneously static and dynamic. It is based on gradual promotion, innovations, drive for improvement. The «Theory of mutual motivation of six networks» strategy is based on interrelation. Each network is separate but effect from the combination of six networks is not unitary. The «Theory of mutual motivation of six networks» is developed to perform successful activity in many spheres; it is universally applied to legislation, rules, culture, traditions and habits, educational systems as well as business in any country and region. 
In Russian pedagogical practice the idea of network cooperation of educational institutions appeared at the end of 1990s due to A. I. Adamsky and educational network «Evrika» created by him.

In respect of educational sphere A. I. Adamsky distinguishes the following characteristics of «network cooperation» in opposition to non-network one. There is not information itself but a person and event in the center of network cooperation. Persons can be author teams, bearers of innovative pedagogical technologies. The second component is «event» that presupposes orientation to solution of some task and which event is initiated for. At the same time, the event is initiated by persons claiming the need to solve this task. According to Adamsky, network cooperation of educational institutions significantly differs from hierarchy cooperation functioning in the modern educational system. The norms of activity are not set «from above», but develop naturally from inside the network of educational institutions based on realities of activity of each participant of the network.

Modern researches of general issues of cooperation of network organizations and prospect of their development are carried out by V. A. Bianki, P. Ziber, M. Castells, N. F. Radionova, L. V. Smorgunov, R. Rodes etc. The methodology of network organization in interrelation with innovation processes in education was developed by A. I. Adamsky, K. G. Mitrofanov, A. A. Pinsky, G. N. Prozumentovoy. A. O. Zotkin examined the practice of formation of network educational programs. The analysis of experience of network organization of extended professional education is reflected in the works of N. E. Orlikhina. The use of network cooperation for innovation development of educational institutions is presented in the research of $\mathrm{T}$. A. Zubareva.

Canadian researcher S. Downs proposed a new philosophy of distance learning «e-learning 2.0». Connectivism, an educational strategy, appears as a natural reaction to oversaturation of potential information in the network [6]. Believing that the concept of traditional pedagogy is insufficient in the conditions of «horizontal» (decentralized) education activity and joint learning («peer education»), J. Corneli and $\mathrm{Ch}$. Danoff proposed a new theory of educational activity called paragogy.

Connectivism is one of the approaches in the sphere of artificial intelligence, neurobiology, psychology and philosophy of mind. Connectivism is based on the theories of network, chaos, elaborate and self-organizing systems. G. Siemens and S. Downs continue the ideas set forth by a German philosopher V. Flusser. Connectivism is based on a hypothesis that mental phenomena can be described with networks of simple interrelated elements.

Personality is essential for connectivism. However, the process of learning cannot be under its control completely. The learning can be supported from outside and take place along with attraction of potential information sources. Thus, connectivism emphasizes unstable dynamic nature of learning. Learning is a process of network creation (according to S. Downs, learning involves adding oneself to a network).
Basic characteristics of network educational organization (according to M. M. Chuchkevich):

1. Independence of network members - members of an organization have a certain level of freedom, sufficient to be able to decide on priorities according to the nature and direction of their activity and bear responsibility for a final result. Two types of responsibility are essential: responsibility towards oneself for personal success and the result of achievement of a personally set goal and neped towards an authority body for achievement of a result set in accordance with the goal set in turn from outside.

2. Plurality of leaders - the notion of a leader in the network does not coincide with the notion of leadership in organizations built in accordance with the principle of administrative hierarchy. The leader in a network organization is any person or educational institution, which is a bearer of scientific and methodological, financial, production, communicative, expert or any other resource. An important condition of leadership in the network is the readiness of a network member to use their resource in order to achieve common goals of the network, naturally in parallel to realization of their own goals. In organizations built in accordance with network principles the profile of leadership system is almost constantly in the process of change. One should have a resource required for work to achieve leadership in the network. This very fact ensures the plurality of leadership levels.

3. Uniting network - it is quite a difficult phenomenon in network organizations, which comes laden with sense of functional base of network ideologem - competitive cooperation. Uniting goal in a network organization is built on an individual progress of each network member achieved out of network. As a rule, uniting goal is based on the interest of network members in use of joint educational, status, material, marketing and information resources of the network. A relatively independent educational institution joins a network organization going from the field of competition to the field of joint cooperation with other independent members of the network only because it sees competitive pragmatic benefit for itself within the network in comprehensible out of its field of activity.

4. Voluntary relations - take different forms depending on the type of network organization and level of independence of its participants. It is understood that teachers relying upon unlimited but present right of choice of partners for a project team and taking responsibility for their resource position independently determine the structure of their cooperation within network educational program on certain projects.

5. Plurality of cooperation levels - cooperation within the frames of network is carried out not through administrative channels, but directly between those companies and people who should solve required issue together. Cooperation appears directly through the lines of current demand of cooperation. In this respect, there is real plurality of cooperation levels as each member of the network can cooperate with both members of their cell (level) and representatives of other levels, which can 
be located far from or close to the corporate center of the network.

Pace of development of network cooperation at different levels of education system are not even. More active development of network cooperation takes place at the level of educational institutions of general education. In the system of professional education these tendencies are only being formed. Thus, for example, the project «Network University of CIS» was established in 2008 by Interstate Fund of human cooperation (IFHC) and active contribution from Peoples' Friendship University of Russia and its rector V. Filippov. The project involved 16 higher education institutions from eight CIS countries. However, this is only one direction of development of network cooperation of higher education institutions in CIS countries that solves the problem of training of bachelor's degree holders and specialists.

«Network cooperation of higher education institutions on major directions of Bologna process on the basis of information and communication technologies» is in the progress (the coordinator of this project is National fund for staff training). Information support of the project is performed by State Institute of Information Technologies and Telecommunications «Informika».

Acting as initiators of network cooperation, universities solve the following issues [7, 8]:

- expansion of the range of educational services in order to realize individual educational demands of the students;

- preservation and (or) expansion of enrollment of students;

- provision of highly qualified science and pedagogy staff for educational process purposes;

- implementation of new forms of organization of research activity, educational process and new forms of evaluation of students' achievements;

- attraction of extra-budgetary funds.

The technology of use of network cooperation includes the complex of the following activities:

- joint planning of educational programs;

- joint design of educational network;

- unified methodical accompaniment in educational network;

- joint methodical design;

- corporate expertise;

- creation of unified information environment;

- construction and expansion of the system of horizontal relations, including external partners of education network;

- collective forms of communication, management of educational network, joint decisionmaking;

- organization of activity of resource center, allowing using of network cooperation as resource of personal and professional development.

D. Weinberger emphasizes: «as knowledge becomes networked, the smartest person in the room isn't the person standing at the front lecturing us, and isn't the collective wisdom of those in the room. The smartest person in the room is the room itself: the network that joins the people and ideas in the room, and connects to those outside of it. It's not that the network is becoming a conscious super-brain. Rather, knowledge is becoming inextricable from - literally unthinkable without - the network that enables it...».

Two groups of conditions to ensure network efficiency cooperation in the field of education:

- organization and content-related condition: dynamic structure of network educational programs; developed horizontal and diagonal relations between the network elements; constant monitoring of educational demands of students, network resources and employers' requests; partner relations between subjects of educational activity; preparedness of teachers supervising network programs; local regulatory and legal base ensuring the functioning and development of educational network; - motivation and value conditions: prospects of professional growth for students; consideration of educational demands of students; variety of educational modules ensuring satisfaction of students' needs and regional employers' demands; personality-oriented information and education environment; value and sense dialogue cooperation; innovation technological methods activating informative and cognitive independence of students.

We consider the following as key characteristics of network cooperation [9]:

- space, allows describing of variety of horizontal and vertical cooperation in the network;

- information, reveals the content of this cooperation;

- time, shows the logic of development of network relations;

- form, represents different variants of network activity.

Resource provision of network educational cooperation includes four components:

- educational resource (interactive multimedia network basic educational courses; interactive multimedia network profession-oriented educational courses; interactive laboratory practicum of remote access; project tasks bank; interactive author (variation) courses; hybrid library with a wide range of digital educational resources; data bases; interactive training devices; interactive tests);

- human resource (curators of network educational projects (programs); network academic consultants; network tutors);

- functional resource (electronic journals; forums; statistics base);

- technical resource (computers; printers; scanners; projectors; web-cams; screens; Internet access).

Involving the sources of potential information, the student forms personal (individual) education network PLN (personal learning network). The learning is doe through many channels as different relations are used to deliver educational material. Development of informative and cognitive independence is one of the key pedagogical tasks for modern education system as the ability to learn something new I more important than current knowledge that we possess (ability to enrich knowledge is more important than the static system of accumulated knowledge) [10]. 


\section{Conclusions}

Various approaches and personal skills are required for effective learning in modern society: for example, ability to make relations and see the sense between spheres of knowledge, concepts and ideas is one of the major skills ensuring effective activity in the modern world. Timely renewal of knowledge is a necessary feature of modern education. Moreover, this is a process of decisionmaking (ability to choose, analyze, organize, classify, evaluate incoming information), which presupposes high level of development of informative and cognitive independence of students' personality.

\section{References}

1. I.V. Robert, Modern information technologies in education: didactic problems; prospects of application (1994)

2. T.A. Olkhovaya, V.A. Sadovaya, Higher Education Today, 1 (2011)
3. M. Castells, The Information Age: Economy, Society and Culture (2000)

4. Casper L. ASEE Prism, 9(4), 30 (1999)

5. R. Stichweh, Journal of sociology and social anthropology, 2 (1999).

6. G. Siemens, International Journal of Instructional Technology \& Distance Learning, 2 (2005)

7. V.I. Soldatkin, A look at trends in e-learning development in Russia, In Proc. Educational environment today and tomorrow (2014)

8. G.G. Bubnov, E.V. Pluzhnik, V.I. Soldatkin, Regulatory support of e-learning in Russia, Cloud of Science, 2, 5 (2013)

9. V.N. Eliseev, Information search in the Internet environment as a factor of development of informative independence of students of high school (Pedagogical House, Moscow, 2015).

10. G.G. Bubnov, E.V. Nikulchev, E.V. Pluzhnik, H. Edu. in Rus., 1, 159 (2015). 